\title{
Perioperative cardiac events in patients undergoing noncardiac surgery: a review of the magnitude of the problem, the pathophysiology of the events and methods to estimate and communicate risk
}

\author{
P.J. Devereaux, Lee Goldman, Deborah J. Cook, Ken Gilbert, Kate Leslie, Gordon H. Guyatt
}

Abstract

THIS IS THE FIRST OF 2 ARTICLES EVALUATING cardiac events in patients undergoing noncardiac surgery. In this article, we review the magnitude of the problem, the pathophysiology of these events, approaches to risk assessment and communication of risk. The number of patients undergoing noncardiac surgery worldwide is growing, and annually 500000 to 900000 of these patients experience perioperative cardiac death, nonfatal myocardial infarction (MI) or nonfatal cardiac arrest. Although the evidence is limited, a substantial proportion of fatal perioperative Mls may not share the same pathophysiology as nonoperative Mls. A clearer understanding of the pathophysiology is needed to direct future research evaluating prophylactic, acute and long-term interventions. Researchers have developed tools to facilitate the estimation of perioperative cardiac risk. Studies suggest that the Lee index is the most accurate generic perioperative cardiac risk index. The limitations of the studies evaluating the ability of noninvasive cardiac tests to predict perioperative cardiac risk reveals considerable uncertainty as to the role of these popular tests. Similarly, there is uncertainty as to the predictive accuracy of the American College of Cardiology / American Heart Association algorithm for cardiac risk assessment. Patients are likely to benefit from improved estimation and communication of cardiac risk because the majority of noncardiac surgeries are elective and accurate risk estimation is important to allow informed patient and physician decision-making.

CMAJ 2005;173(6):627-34

$\mathrm{T}$ 1 hroughout the last few decades noncardiac surgery has made substantial advances in treating diseases (e.g., cancer) and improving patient quality of life (e.g., arthroplasty). As a result, the number of patients undergoing noncardiac surgery is growing worldwide. ${ }^{1}$ However, such surgery is associated with significant cardiac morbidity, mortality and consequent cost.

This is the first of 2 articles evaluating major perioperative cardiac events in patients undergoing noncardiac surgery. In this article, we review the magnitude of the problem, the pathophysiology of these events, approaches to perioperative risk assessment and the communication of risk. In the second article, we will present evidence regarding monitoring strategies for perioperative myocardial in- farction (MI), propose diagnostic criteria for perioperative $\mathrm{MI}$ and review the evidence for perioperative prophylactic cardiac interventions.

The breadth of the topics covered in this article prohibited a fully systematic approach to this review. Although this is a narrative review, we did conduct thorough literature searches in each area and contacted the authors of relevant articles when necessary. We sought relevant systematic reviews and have highlighted their findings in our discussion. Our methods and attempt to focus on systematic reviews distinguish our review from several others, ${ }^{2-4}$ which may explain why we often reached different conclusions.

\section{Magnitude of risk of major perioperative cardiac events}

Patients undergoing noncardiac surgery are at risk of major perioperative cardiac events (cardiac death, nonfatal MI and nonfatal cardiac arrest). Patients experiencing an MI after noncardiac surgery have a hospital mortality rate of $15 \%-25 \%,-8$ and nonfatal perioperative $\mathrm{MI}$ is an independent risk factor for cardiovascular death and nonfatal MI during the 6 months following surgery (hazard ratio 18; 95\% confidence interval [CI $6-57) .{ }^{9}$ Patients who have a cardiac arrest after noncardiac surgery have a hospital mortality rate of $65 \%,{ }^{10}$ and nonfatal perioperative cardiac arrest is a risk factor for cardiac death during the 5 years following surgery. ${ }^{11}$

Table 1 presents the proportion of patients undergoing noncardiac surgery who experienced a major cardiac event in prospective cohort studies with samples of more than 300 patients that did not have restrictions as to the type of surgery (e.g., vascular surgery) and that required patients to have at least 1 measurement of a cardiac enzyme or biomarker after surgery. ${ }^{5-8,12-14}$ We included only studies that required such measurement after surgery because perioperative MI occurs primarily during the first 3 days after surgery, ${ }^{7,15}$ a period when the majority of patients are receiving narcotic therapy and therefore may not experience cardiac symptoms during their MI. ${ }^{6,7,16}$

The pooled results from the studies evaluating patients who had or were at risk of cardiac disease ${ }^{-8,12,13}$ suggest that 
$3.9 \%$ (95\% CI $3.3 \%-4.6 \%$ ) of these patients experience major perioperative cardiac events. The study by Lee and colleagues $^{14}$ is the only study in Table 1 that included relatively unselected patients (i.e., it was not limited to patients referred to a medical consult service or to patients with or at risk of coronary artery disease). Their findings suggest that major perioperative cardiac events occur in $1.4 \%$ (95\% CI $1.0 \%-1.8 \%$ ) of adults 50 years of age or older undergoing elective noncardiac surgery requiring hospital admission.

There are a number of reasons why the time frames of the studies reported in Table 1 - most were conducted over a decade ago - limit their ability to inform us about the current incidence of major perioperative cardiac events. First, patients with coronary artery disease are now living longer as a result of major medical advances. ${ }^{17}$ Therefore, patients with high burdens of coronary artery disease are now surviving long enough for other conditions to develop that require surgical consideration, including cancer and severe osteoarthritis of the hip and knee. Second, there has been a shift in practice patterns toward advanced medical care (including surgery) for elderly patients. Third, some surgical interventions have become less invasive.

Despite these limitations, results from the study by Lee and colleagues likely represent a conservative estimate of the current incidence of major perioperative cardiac events among unselected adults undergoing noncardiac surgery that requires hospital admission. We say conservative be- cause of the authors' exclusion of emergent surgical cases and the increasing numbers of elderly people undergoing noncardiac surgery today. Emergent cases represent about $10 \%$ of noncardiac surgeries, ${ }^{18}$ and patients undergoing emergent surgery are at higher risk of major perioperative cardiac events than patients undergoing elective surgery (odds ratio 2.6, 95\% CI 1.2-5.6).

About 100 million adults worldwide undergo noncardiac surgery annually. ${ }^{1}$ Conservative assumptions suggest that half of these patients are in an at-risk age group ${ }^{1}$ and that the results from the study by Lee and colleagues ${ }^{14}$ reflect their cardiac risk. Therefore, each year it is likely that 500000 to 900000 patients worldwide experience perioperative cardiac death, nonfatal MI or nonfatal cardiac arrest. This problem is important because of the burden of illness it represents and the health resources it consumes: perioperative cardiac complications prolong hospital stays by a mean of 11 days ( $95 \%$ CI $9-12$ days). ${ }^{15}$

\section{Pathophysiology of perioperative cardiac events}

\section{Cardiac death}

In studies that examined perioperative cardiac death, authors attributed the cause to $\mathrm{MI}$ in $66 \%$ of the cases and to

Table 1: Outcomes of major perioperative cardiac events in patients undergoing noncardiac surgery

\begin{tabular}{|c|c|c|c|c|c|c|}
\hline \multirow[b]{2}{*}{ Study } & \multirow[b]{2}{*}{ Patient population } & \multirow[b]{2}{*}{$\begin{array}{l}\text { Enrolment } \\
\text { years }\end{array}$} & \multicolumn{4}{|c|}{ Outcome; no. (\%) of patients } \\
\hline & & & $\begin{array}{l}\text { Cardiac } \\
\text { death }\end{array}$ & MI* & $\begin{array}{l}\text { Cardiac } \\
\text { arrest }\end{array}$ & $\begin{array}{c}\text { Major cardiac } \\
\text { outcome } \dagger\end{array}$ \\
\hline \multicolumn{7}{|c|}{ Studies evaluating patients with or at risk of cardiac disease } \\
\hline Detsky et al ${ }^{12}$ & $\begin{array}{l}455 \text { consecutive patients aged }>40 \mathrm{yr} \\
\text { evaluated by general medical service for } \\
\text { perioperative cardiac risk }\end{array}$ & 1983-1985 & $11(2.4)$ & $14(3.1)$ & 0 & $25(5.5)$ \\
\hline Shah et $\mathrm{al}^{5}$ & $\begin{array}{l}688 \text { consecutive patients aged }>70 \mathrm{yr} \text { with } \\
\text { cardiac disease }\end{array}$ & 1986-1987 & $15(2.2)$ & $32(4.7)$ & NA & $40(5.8)$ \\
\hline Mangano et $\mathrm{al}^{13}$ & $\begin{array}{l}474 \text { consecutive men with CAD or } 2 \text { risk } \\
\text { factors for CAD; patients undergoing } \\
\text { nonelective surgery were excluded }\end{array}$ & 1987-1988 & $6(1.3)$ & $12(2.5)$ & NR & $13(2.7)$ \\
\hline Ashton et $\mathrm{al}^{6}$ & $\begin{array}{l}835 \text { consecutive men aged } \geq 40 \text { yr with CAD, } \\
\text { cerebral or peripheral atherosclerosis, or risk } \\
\text { factors for CAD; patients undergoing emergent } \\
\text { surgery were excluded }\end{array}$ & 1987-1989 & $9(1.1)$ & $15(1.8)$ & NA & $20(2.4)$ \\
\hline 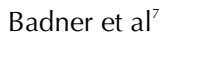 & $\begin{array}{l}323 \text { consecutive patients aged } \geq 50 \mathrm{yr} \\
\text { with CAD }\end{array}$ & 1993-1996 & $3(0.9)$ & $18(5.6)$ & 0 & $18(5.6)$ \\
\hline Kumar et $\mathrm{al}^{8}$ & 1121 patients with known or suspected CAD & 1992-1995 & $8(0.7)$ & $31(2.8)$ & $7(0.6)$ & $36(3.2)$ \\
\hline All & & & $52(1.3)$ & $122(3.1)$ & $7(0.2)$ & $152(3.9)$ \\
\hline \multicolumn{7}{|c|}{ Study evaluating relatively unselected patients } \\
\hline Lee et $\mathrm{al}^{14}$ & $\begin{array}{l}4315 \text { patients aged } \geq 50 \mathrm{yr} \text { with expected } \\
\text { postoperative length of stay } \geq 48 \mathrm{~h} \text {; patients } \\
\text { undergoing emergent surgery were excluded }\end{array}$ & 1989-1994 & $12(0.3)$ & $46(1.1)$ & $16(0.4)$ & $59(1.4)$ \\
\hline
\end{tabular}

Note: $\mathrm{MI}=$ myocardial infarction, $\mathrm{CAD}=$ coronary artery disease, $\mathrm{NA}=$ author contacted but unable to provide data, $\mathrm{NR}=$ not reported

*Various definitions of MI were used across the studies, which may account for some of the variation in event rates.

†Composite of cardiac death, nonfatal myocardial infarction and nonfatal cardiac arrest. 
arrhythmia or heart failure in 34\% (Table 1). However, none of these studies used formal criteria to establish the underlying causes of cardiac death or determined intrarater reliability. ${ }^{5-8,13}$ In addition, it is unclear whether ischemia, arrhythmia or a pre-existing cardiomyopathy caused heart failure that resulted in death. Further well-designed studies are needed to determine accurately the frequency with which these events cause perioperative cardiac death and to elucidate other causes.

\section{Cardiac arrest}

We identified only 1 study that examined the cause of cardiac arrest in patients undergoing noncardiac surgery. ${ }^{10}$ Sprung and colleagues evaluated 223 cases of perioperative cardiac arrest that occurred between the start of anesthesia and discharge from the recovery room in patients undergoing noncardiac surgery at a single centre from 1990 to 2000. A committee of staff anesthesiologists, anesthesia chief residents, certified nurse anesthetists and recovery room nurses reviewed all cases and judged the probable cause of each cardiac arrest. The dominant causes were cardiac causes (e.g., MI) and bleeding (Table 2). Confidence in these conclusions will require a multicentre study of all cardiac arrests that occur in the postoperative period (i.e., from the start of surgery to 30 days after surgery).

\section{Myocardial infarction}

Arterial thrombosis is the underlying cause of the majority of nonoperative MIs. ${ }^{19}$ In $64 \%-100 \%$ of patients with nonoperative MIs, coronary artery plaque fissuring occurs, ${ }^{20,21}$ and in $65 \%-95 \%$ there is an acute luminal thrombus. ${ }^{21-25}$ The pathophysiology underlying MIs in the operative setting is less clear.

\section{Interpretation of coronary pathology and angiography data}

Two studies of the coronary pathology underlying fatal perioperative MI revealed that two-thirds of the patients had significant left main or 3-vessel coronary artery disease. ${ }^{26,27}$ These studies also showed that most of the patients

\begin{tabular}{|c|c|c|}
\hline Probable cause & $\begin{array}{l}\text { No. of } \\
\text { patients }\end{array}$ & $\%(95 \% \mathrm{Cl})$ \\
\hline Bleeding & 78 & 35 (29-42) \\
\hline Cardiac* & 98 & $44(37-51)$ \\
\hline Other† & 47 & $21(16-27)$ \\
\hline
\end{tabular}

did not exhibit plaque fissuring and only about one-third had an intracoronary thrombus. These findings suggest that a substantial proportion of these fatal perioperative MIs may have resulted from an increase in oxygen demand in the setting of fixed coronary artery stenoses. ${ }^{28}$ In contrast, a study involving patients who underwent coronary angiography before vascular surgery revealed that the majority of nonfatal perioperative MIs occurred in arteries without high-grade stenoses. These findings suggest that the events may have resulted from plaque fissuring and acute coronary artery thrombosis. ${ }^{29}$ Given the conflicting evidence, further study is needed to establish the pathophysiology of fatal and nonfatal perioperative MIs; this area of investigation would gain important insights from a study in which all patients experiencing perioperative MI underwent acute coronary angiography.

\section{Triggers of perioperative myocardial infarction}

Surgery, with its associated trauma, anesthesia and analgesia, intubation and extubation, pain, hypothermia, bleeding and anemia, and fasting, is analogous to an extreme stress test. Fig. 1 illustrates how these factors initiate inflammatory, hypercoagulable, stress and hypoxic states, which are associated with perioperative elevations in troponin levels, arterial thrombosis and mortality. ${ }^{30-35}$

Increasing grades of surgical trauma and general anesthesia can initiate inflammatory and hypercoagulable states. ${ }^{31,36-39}$ The inflammatory state involves increases in tumour necrosis factor- $\alpha$, interleukin (IL)-1, IL-6 and Creactive protein; these factors may have a direct role in initiating plaque fissuring and acute coronary thrombosis. ${ }^{38,40-42}$ The hypercoagulable state involves increases in plasminogen activator inhibitor-1, factor VIII and platelet reactivity, as well as decreases in antithrombin III; all of these factors can lead to acute coronary thrombosis. ${ }^{31,43,44}$

The stress state involves increased levels of catecholamines (epinephrine and norepinephrine) and cortisol. Perioperative catecholamine and cortisol levels increase with general anesthesia, anesthetic reversal, extubation, increasing pain scores, increasing grades of surgical trauma, anemia, fasting and hypothermia. ${ }^{45-50}$ Increased stress hormone levels result in increases in blood pressure, heart rate, coronary artery sheer stress, relative insulin deficiency and free fatty acid levels. ${ }^{33,50,51}$ Coronary artery shear stress may trigger plaque fissuring and acute coronary thrombosis. ${ }^{50}$ The other factors increase oxygen demand and can result in perioperative myocardial ischemia, which is strongly associated with perioperative $M I^{13,52,53}$

Factors that can initiate a hypoxic state include anemia, hypothermia (through shivering), and anesthesia and analgesia (through suppression of breathing). ${ }^{54-56}$ Perioperative hypoxia can result in myocardial ischemia in the setting of a hemodynamically significant coronary artery stenosis.

Further research is needed to determine which of these potential triggers are independent risk factors for perioper- 
ative $\mathrm{MI}$ and to assess other potential triggers. To determine whether suppression of these triggers will prevent perioperative MIs will require large randomized trials.

\section{Preoperative cardiac risk assessment}

Although no research has documented its benefits, preoperative cardiac risk assessment may serve an important function. The majority of noncardiac surgeries are elective, and an accurate estimate of risk would facilitate informed patient and physician decision-making. For example, if an elderly woman with multiple risk factors undergoing hip arthroplasty for osteoarthritis were accurately informed that her risk of a major perioperative cardiac event was
$10 \%-12 \%$, she might decide to delay surgery and live with her suboptimal quality of life until her granddaughter graduates in 1 year. Further, accurate risk estimates provide guidance for perioperative management, including the choice of surgical techniques and the location and intensity of postoperative care.

\section{Clinical indices}

Two types of clinical indices - generic and Bayesian exist to estimate the risk of a major perioperative cardiac event in patients undergoing noncardiac surgery. The various published generic indices (Lee, Goldman, Larsen and Gilbert indices) estimate a patient's risk through determi-

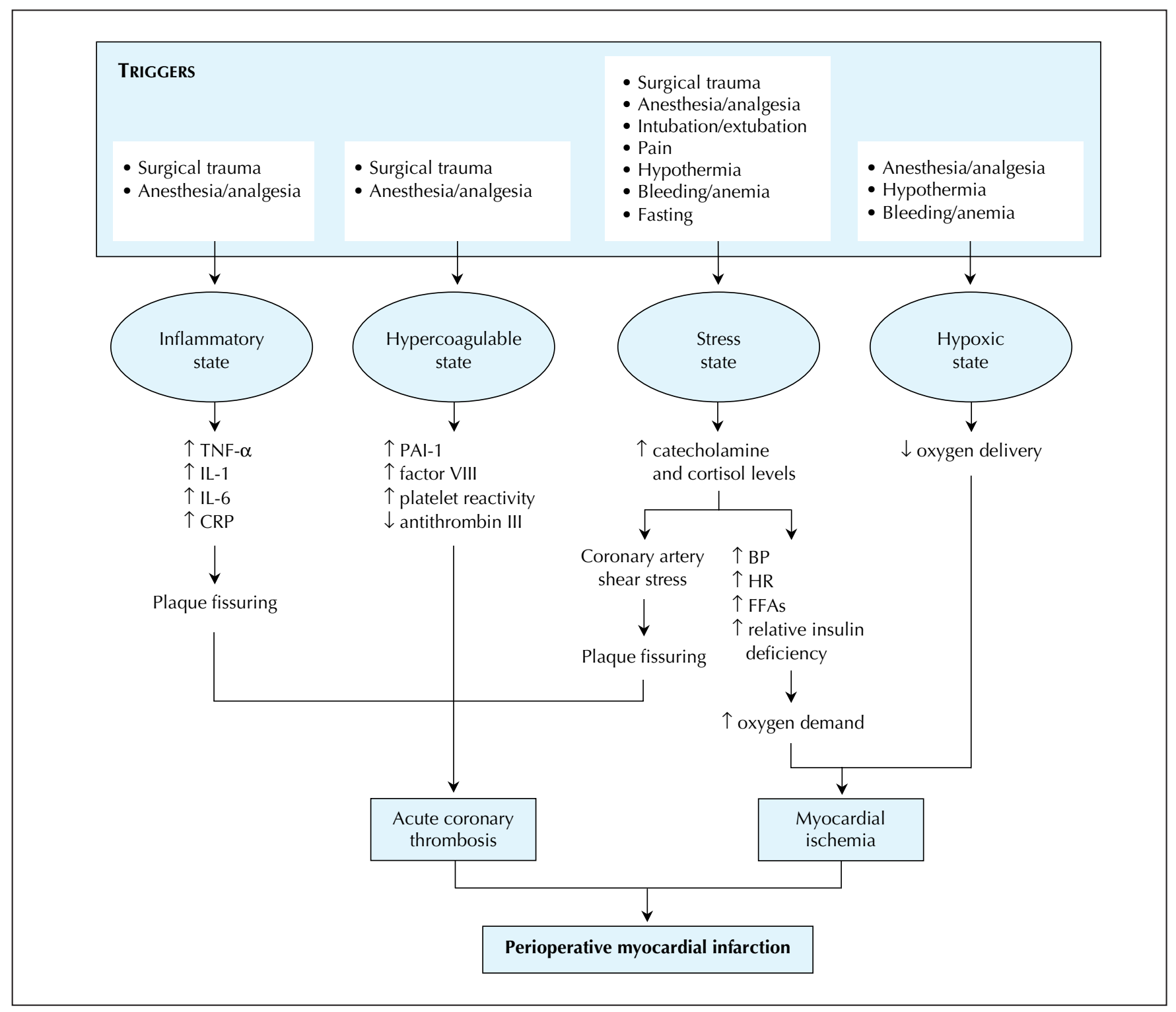

Fig. 1: Potential triggers of states associated with perioperative elevations in troponin levels, arterial thrombosis and fatal myocardial infarction. TNF- $\alpha=$ tumour necrosis factor- $\alpha, \mathrm{IL}=$ interleukin, CRP $=$ C-reactive protein, PAI- $1=$ plasminogen activator inhibitor-1, $\mathrm{BP}=$ blood pressure, $\mathrm{HR}=$ heart rate, FFAs = free fatty acids. 
nation of how many predictors of risk (e.g., history of angina, diabetes, emergent surgery) the patient has. ${ }^{14,57-59}$ The published Bayesian risk indices (Kumar and Detsky indices) modify the hospital's average cardiac event rate for a specific surgery (pretest probability) through use of a patient's individual index score (likelihood ratio), which is based on how many predictors of risk (e.g., history of angina, diabetes) the patient has; this results in an estimate of the patient's risk of a perioperative cardiac event (posttest probability). ${ }^{8,12}$

Although several studies have compared the predictive accuracy of the generic and Bayesian risk indices, $8,12,14,59,60$ only 2 have used contemporary pretest probabilities based on data from the hospitals studied at that time. ${ }^{8,12}$ These 2 studies revealed superior prediction capabilities of the Bayesian risk indices. ${ }^{8,12}$ Although these studies fulfill the methodologic criteria of a clinical prediction rule study, ${ }^{61}$ only the Detsky index has shown consistent results in a separate setting, although this validation is limited to 1 high-

\begin{tabular}{lc}
\hline $\begin{array}{l}\text { Table 3: Estimated risk of a major perioperative cardiac event* } \\
\text { based on predictors in the Lee index }\end{array}$ \\
\hline $\begin{array}{l}\text { No. of } \\
\text { risk factors } \dagger\end{array}$ & $\begin{array}{l}\text { Risk of major perioperative } \\
\text { cardiac event, \% }(95 \% \mathrm{Cl})\end{array}$ \\
\hline 0 & $0.4(0.1-0.8)$ \\
1 & $1.0(0.5-1.4)$ \\
2 & $2.4(1.3-3.5)$ \\
$\geq 3$ & $5.4(2.8-7.9)$ \\
\hline
\end{tabular}

*Includes cardiac death, nonfatal myocardial infarction and nonfatal cardiac arrest. Not included in this table are postoperative cardiogenic pulmonary edema and complete heart block, which are included as outcomes in the Lee index.

†Risk factors include high-risk surgery (intraperitoneal, intrathoracic or suprainguinal vascular surgery); history of ischemic heart disease (defined as a history of myocardial infarction, positive exercise test result, current complaint of ischemic chest pain or nitrate use, or electrocardiogram showing pathological Q waves; patients who had undergone prior coronary bypass surgery or angioplasty were included only if they had such findings after their procedure); history of congestive heart failure (defined as a history of heart failure, pulmonary edema or paroxysmal nocturnal dyspnea; an $\mathrm{S} 3$ gallop or bilateral rales on physical examination; or chest radiograph showing pulmonary vascular resistance); history of cerebrovascular disease (stroke or transient ischemic attack); use of insulin therapy for diabetes; and preoperative serum creatinine level $>175 \mu \mathrm{mol} / \mathrm{L}$ (> $2.0 \mathrm{mg} / \mathrm{dL}$ ).

Table 4: Results of meta-analysis evaluating ability of noninvasive cardiac tests to predict risk of perioperative cardiac events in patients undergoing vascular surgery*

\begin{tabular}{|c|c|c|c|c|c|}
\hline Test & $\begin{array}{l}\text { No. of } \\
\text { studies }\end{array}$ & $\begin{array}{c}\text { No. of } \\
\text { patients }\end{array}$ & $\begin{array}{l}\text { No. of } \\
\text { events }\end{array}$ & $\begin{array}{l}\text { Sensitivity, } \\
\%(95 \% \mathrm{Cl})\end{array}$ & $\begin{array}{l}\text { Specificity, } \\
\%(95 \% \mathrm{Cl})\end{array}$ \\
\hline Radionuclide ventriculography & 8 & 532 & 54 & $50(32-69)$ & $91(87-96)$ \\
\hline $\begin{array}{l}\text { Ambulatory } \\
\text { electrocardiography }\end{array}$ & 8 & 893 & 52 & $52(21-84)$ & $70(57-83)$ \\
\hline Exercise electrocardiography & 7 & 685 & 25 & $74(60-88)$ & $69(60-78)$ \\
\hline $\begin{array}{l}\text { Myocardial perfusion } \\
\text { scintigraphy }\end{array}$ & 23 & 3119 & 207 & $83(77-89)$ & $49(41-57)$ \\
\hline $\begin{array}{l}\text { Dobutamine stress } \\
\text { echocardiography }\end{array}$ & 8 & 1877 & 82 & $85(74-97)$ & $70(62-79)$ \\
\hline $\begin{array}{l}\text { Dipyridamole stress } \\
\text { echocardiography }\end{array}$ & 4 & 850 & 33 & $74(53-94)$ & $86(80-93)$ \\
\hline
\end{tabular}

*This table has been modified, with permission, from the original, which appeared in reference 62 (Kertai MD, Boersma E, Bax JJ, Heijenbrok-Kal MH, Hunink MG, L'Talien GJ, et al. A meta-analysis comparing the prognostic accuracy of six diagnostic tests for predicting perioperative cardiac risk in patients undergoing major vascular surgery. Heart 2003;89:1327-34). @ BMJ Publishing Group Ltd. and British Cardiac Society. quality single-centre study. ${ }^{8}$ However, the current predictive accuracy of the Detsky index is uncertain, because no highquality studies have established contemporary complication rates for individual surgeries, and it is unknown whether contemporary complication rates at one institution are generalizable to others. Because of the limitations of the available data (e.g., most of the studies occurred at single university hospitals, and most did not focus on composite outcomes with more or less equally important components), determining the optimal risk index to predict major perioperative cardiac events will require a multicentre study that includes several university and nonuniversity hospitals.

Until more definitive research becomes available, clinicians require a practical clinical index to facilitate perioperative cardiac risk estimation. The Lee index is the best validated and most accurate predictive generic risk index, and it is simple to use in clinical practice. ${ }^{14}$ It consists of 6 equally weighted cardiovascular risk factors: high-risk surgery (intraperitoneal, intrathoracic or suprainguinal vascular surgery), history of ischemic heart disease, history of congestive heart failure, history of cerebrovascular disease (stroke or transient ischemic attack), use of insulin therapy for diabetes and a preoperative serum creatinine level of more than $175 \mu \mathrm{mol} / \mathrm{L}$ (> $2.0 \mathrm{mg} / \mathrm{dL})$. Table 3 shows the estimated risk of a major perioperative cardiac event based on the number of risk factors met. Although there are many positive aspects of the Lee index, the study that derived and validated it had limitations (it excluded emergent surgeries and surgical cases with an expected length of stay of less than 2 days during the years 1989-1994).

\section{Noninvasive testing}

Table 4 presents the results from a recent meta-analysis that evaluated the prognostic accuracy of 6 noninvasive tests for predicting perioperative cardiac death or nonfatal MI in patients undergoing vascular surgery. ${ }^{62}$ The results suggested a trend toward superior prognostic accuracy with dobutamine stress echocardiography compared with the other tests, but this trend was statistically significant only in comparison with myocardial perfusion scintigraphy. These results warrant cautious interpretation for the following reasons: the majority of studies included in the meta-analysis used weak methods (e.g., retrospective design, failure to blind individuals interpreting the test results to the clinical predictors of risk, and failure to blind the outcome assessors to the test results); the cumulative event rate for most of the tests was low; there was significant heterogeneity across the study results for 
individual tests; and test results were analyzed using a single threshold (i.e., results were dichotomized as positive or negative).

The relevance of this last limitation is highlighted in another recent meta-analysis that evaluated semiquantitative dipyridamole myocardial stress perfusion imaging for predicting perioperative cardiac death or nonfatal MI in patients undergoing vascular surgery ${ }^{63}$ This meta-analysis included 9 studies evaluating 1179 patients, of whom 82 experienced cardiac death or nonfatal MI. Rather than considering test results as positive or negative, variation in the likelihood ratios were shown based on the extent of reversibility of myocardial defects (Table 5). In the setting of a diagnostic study, many would not consider variations in likelihood ratios of 0.42 to 2.9 of much relevance. In evaluating prognostic information, however, a patient or physician may value the ability to distinguish between a perioperative risk of a major cardiovascular outcome of 3\%, 7\% or $18 \%$, so to them the test and its results are relevant (Table 5). Narrowing the confidence intervals for these results, and determining more precisely the number of patients who are likely to have the various proportions of reversible myocardial defects, will require further highquality research.

The limitations of the studies evaluating the ability of noninvasive cardiac tests to predict perioperative risk leaves considerable uncertainty concerning the role of these popular tests before noncardiac surgery. Until investigators undertake further research, some physicians may want to consider noninvasive cardiac testing in patients who have severe exercise restrictions (e.g., patients with severe claudication) that limit the clinical assessment of symptoms suggestive of coronary artery disease.

When considering which noninvasive cardiac test to order, physicians may want to consider the following: the results of the relevant meta-analyses, and their limitations; the uncertain utility of noninvasive tests in patients undergoing nonvascular, noncardiac surgery; what tests and expertise are available at their hospital; what test a patient can undertake (e.g., patients with severe claudication are probably unable to complete an exercise electrocardiographic stress test); and the likelihood of an important change in risk estimation (e.g., physicians using the Lee index should use a noninvasive test to refine the risk estimate only if the refined risk estimate, based on the potential test results, would be interpreted by the patient or physician as important). To illustrate the last point, if the results of the metaanalysis evaluating semiquantitative dipyridamole myocardial stress perfusion imaging in patients undergoing vascular surgery (Table 5) are applicable to other types of surgery, use of this noninvasive test in patients undergoing nonvascular, noncardiac surgery with no risk factors on the Lee index (i.e., a risk estimate of $0.4 \%$ [Table 3]) may result in a refined risk estimate of less than $0.01 \%$ or $5 \%$; for patients with 3 risk factors on the Lee index (i.e., a risk estimate of $5.4 \%$ [Table 3]), the refined risk estimate may be $2 \%$ or $14 \%$.

\section{American College of Cardiology / American Heart Association algorithm for preoperative cardiac risk assessment}

Some authors have recommended that physicians use the American College of Cardiology / American Heart Association (ACC/AHA) algorithm to stratify patients undergoing noncardiac surgery according to their perioperative cardiac risk. ${ }^{64,65}$ It should be noted that this algorithm was not derived from a prospective study; rather, it was derived from the interpretation of data from various studies and the judgments of the committee members. ${ }^{66}$ The few studies that have evaluated the reliability of the ACC/AHA algorithm have limitations: they had few cardiac events; they failed to demonstrate that the algorithm is effective in stratifying cardiac risk across the 3 strata proposed in the algorithm; and they did not compare the predictive accuracy of the ACC/AHA algorithm with the most accurate clinical risk indices (i.e., the Lee and Detsky indices). ${ }^{67,68}$ The recommendations in the ACC/AHA algorithm regarding non-

\begin{tabular}{|c|c|c|c|}
\hline $\begin{array}{l}\text { Extent of reversibility of } \\
\text { myocardial defects }\end{array}$ & $\begin{array}{l}\text { Likelihood ratio } \\
\quad(95 \% \mathrm{Cl})\end{array}$ & $\begin{array}{l}\text { Post-test probability } \dagger \text { of } \mathrm{MI} \text { or } \\
\text { cardiac death, } \%(95 \% \mathrm{Cl})\end{array}$ & $\begin{array}{l}\% \text { of scans with } \\
\text { this result }\end{array}$ \\
\hline No defects & $0.42(0.20-0.88)$ & $3 \quad(1-6)$ & 30 \\
\hline Fixed defects only & $0.51(0.24-1.1)$ & $4 \quad(2-8)$ & 30 \\
\hline Reversibility $<20 \%$ & $1.3 \quad(0.88-1.9)$ & $9 \quad(6-13)$ & 17 \\
\hline Reversibility $20 \%-29 \%$ & $1.6 \quad(1.0-2.6)$ & $11(7-16)$ & 11 \\
\hline Reversibility $30 \%-39 \%$ & $2.9 \quad(1.6-5.1)$ & $18(11-28)$ & 6 \\
\hline Reversibility $40 \%-49 \%$ & $2.9 \quad(1.4-6.2)$ & $18(10-32)$ & 3 \\
\hline Reversibility $\geq 50 \%$ & $11 \quad(5.8-20)$ & $45(30-60)$ & 3 \\
\hline
\end{tabular}

*This table has been modified from the original, which appeared in reference 63 (Etchells E, Meade M, Tomlinson G, Cook D. Semiquantitative dipyridamole myocardial stress perfusion imaging for cardiac risk assessment before noncardiac vascular surgery: a meta-analysis. J Vasc Surg 2002:36:534-40). (C) 2002, with permission from The Society for Vascular Surgery.

†Assumption of pretest probability of $7 \%$ based on mean event rate across all studies in the meta-analysis. 
invasive testing ignore the issue of patient and physician values. As mentioned earlier, noninvasive testing is relevant only if patients or physicians would value the potential magnitude of changes in predicted risk.

\section{How do clinicians define and communicate perioperative cardiac risk?}

A recent survey of 104 general internists performing a high volume of preoperative consultations (mean of 17 per month) provides insights into how physicians communicate and define perioperative cardiac risk. ${ }^{69}$ Of the respondents, $96 \%$ indicated that they informed patients of their perioperative cardiac risk, but $77 \%$ of these respondents indicated that they communicated the risk subjectively (i.e., simply telling patients that they were at low, moderate or high risk). When asked what they meant by low, moderate and high risk, respondents provided 8, 27 and 12 different definitions, respectively. The range of values provided by the respondents for the definitions demonstrated marked variation: from less than $1 \%$ to less than $20 \%$ for low risk, $1 \%$ to $50 \%$ for moderate risk, and more than $2 \%$ to more than $50 \%$ for high risk.

Given the variety of definitions used for low, moderate and high risk, physicians should avoid these terms to prevent misunderstandings. Instead, physicians can tell patients and surgeons the percentage risk of cardiac death, nonfatal MI or nonfatal cardiac arrest or the expected event rate among 100 or 1000 similar patients. Given the uncertainty around the risk estimation data, physicians may also want to present the range of risk consistent with the $95 \%$ CI. For example, a 50-year-old man receiving insulin therapy who is scheduled to undergo a bowel resection would have 2 risk factors according to the Lee index (Table 3); a consultant could convey to the patient and surgeon that the patient's risk of cardiac death, nonfatal MI or nonfatal cardiac arrest is $1.5 \%$ to $3.5 \%$.

\section{Conclusion}

Noncardiac surgery is associated with substantial cardiac mortality, morbidity and consequent cost. Perioperative MIs likely result from triggers that initiate inflammatory, hypercoagulable, hypoxic and stress states. Because the majority of noncardiac surgeries are elective, accurate estimation of risk of perioperative cardiac events is important to allow informed patient and physician decision-making. The Lee index is a practical clinical risk index that physicians can use to facilitate risk estimation. There is significant uncertainty regarding the predictive accuracy of preoperative noninvasive cardiac tests and the ACC/AHA algorithm for cardiac risk assessment. Physicians informing a patient or surgeon about the patient's risk of a major perioperative cardiac event should provide specific risk estimates and avoid assumptions associated with subjective classifications of risk.
This article has been peer reviewed.

From the Departments of Medicine and of Clinical Epidemiology and Biostatistics, McMaster University, Hamilton, Ont. (Devereaux, Cook, Guyatt), the Department of Medicine, University of California, San Francisco, San Francisco, Calif. (Goldman), the Department of Medicine, University of Western Ontario, London, Ont. (Gilbert), the Department of Anaesthesia and Pain Management, Royal Melbourne Hospital, and the Department of Pharmacology, University of Melbourne, Melbourne, Australia (Leslie)

Competing interests: None declared.

Contributors: P.J. Devereaux was responsible for the conception of the manuscript and analysis of the data and wrote the first draft. He and Lee Goldman were responsible for data acquisition. All of the authors contributed to the manuscript's design and interpretation of the data, provided critical revisions to the manuscript and approved the final version.

Acknowledgements: P.J. Devereaux is supported by a Senior Research Fellowship Award from the Canadian Institutes of Health Research. Deborah Cook is a Chair of the Canadian Institutes for Health Research.

\section{References}

1. Mangano D. Peri-operative cardiovascular morbidity: new developments. Bailliere's Clin Anaesthesiol 1999;13:335-48.

2. Krupski WC. Update on perioperative evaluation and management of cardiac disease in vascular surgery patients. 7 Vasc Surg 2002;36:1292-308.

3. Chassot PG, Delabays A, Spahn DR. Preoperative evaluation of patients with, or at risk of, coronary artery disease undergoing non-cardiac surgery. $\mathrm{Br} \mathcal{F}$ Anaesth 2002;89:747-59.

4. Karnath BM. Preoperative cardiac risk assessment. Am Fam Physician 2002;66: 1889-96.

5. Shah KB, Kleinman BS, Rao TL, Jacobs HK, Mestan K, Schaafsma M. Angina and other risk factors in patients with cardiac diseases undergoing noncardiac operations. Anesth Analg 1990;70:240-7.

6. Ashton CM, Petersen NJ, Wray NP, Kiefe CI, Dunn JK, Wu L, et al. The incidence of perioperative myocardial infarction in men undergoing noncardiac surgery. Ann Intern Med 1993;118:504-10.

7. Badner NH, Knill RL, Brown JE, Novick TV, Gelb AW. Myocardial infarction after noncardiac surgery. Anesthesiology 1998;88:572-8.

8. Kumar R, McKinney WP, Raj G, Heudebert GR, Heller HJ, Koetting M, et al. Adverse cardiac events after surgery: assessing risk in a veteran population. 7 Gen Intern Med 2001;16:507-18.

9. Mangano DT, Browner WS, Hollenberg M, Li J, Tateo IM. Long-term cardiac prognosis following noncardiac surgery. The Study of Perioperative Ischemia Research Group. 7AMA 1992;268:233-9.

10. Sprung J, Warner ME, Contreras MG, Schroeder DR, Beighley CM, Wilson GA, et al. Predictors of survival following cardiac arrest in patients undergoing noncardiac surgery: a study of 518294 patients at a tertiary referral center. Anesthesiology 2003;99:259-69.

11. Charlson M, Peterson J, Szatrowski TP, MacKenzie R, Gold J. Long-term prognosis after peri-operative cardiac complications. 7 Clin Epidemiol 1994;47:1389-400.

12. Detsky AS, Abrams HB, McLaughlin JR, Drucker DJ, Sasson Z, Johnston N, et al. Predicting cardiac complications in patients undergoing non-cardiac surgery. 7 Gen Intern Med 1986;1:211-9.

13. Mangano DT, Browner WS, Hollenberg M, London MJ, Tubau JF, Tateo IM. Association of perioperative myocardial ischemia with cardiac morbidity and mortality in men undergoing noncardiac surgery. The Study of Perioperative Ischemia Research Group. N Engl 7 Med 1990;323:1781-8.

14. Lee TH, Marcantonio ER, Mangione CM, Thomas EJ, Polanczyk CA, Cook $\mathrm{EF}$, et al. Derivation and prospective validation of a simple index for prediction of cardiac risk of major noncardiac surgery. Circulation 1999;100:1043-9.

15. Fleischmann KE, Goldman L, Young B, Lee TH. Association between cardiac and noncardiac complications in patients undergoing noncardiac surgery: outcomes and effects on length of stay. Am 7 Med 2003;115:515-20.

16. Charlson ME, MacKenzie CR, Ales K, Gold JP, Fairclough G Jr, Shires GT. Surveillance for postoperative myocardial infarction after noncardiac operations. Surg Gynecol Obstet 1988;167:407-14.

17. Braunwald E. Personal reflections on efforts to reduce ischemic myocardial damage. Cardiovasc Res 2002;56:332-8.

18. Khuri SF, Daley J, Henderson W, Barbour G, Lowry P, Irvin G, et al. The National Veterans Administration Surgical Risk Study: risk adjustment for the comparative assessment of the quality of surgical care. 7 Am Coll Surg 1995; 180:519-31.

19. Falk E, Shah PK, Fuster V. Coronary plaque disruption. Circulation 1995;92: 657-71. 
20. Falk E. Plaque rupture with severe pre-existing stenosis precipitating coronary thrombosis. Characteristics of coronary atherosclerotic plaques underlying fatal occlusive thrombi. Br Heart 7 1983;50:127-34

21. Horie T, Sekiguchi M, Hirosawa K. Coronary thrombosis in pathogenesis of acute myocardial infarction. Histopathological study of coronary arteries in 108 necropsied cases using serial section. Br Heart 7 1978;40:153-61.

22. Sinapius D. Relationship between coronary-artery thrombosis and myocardial infarction. Dtsch Med Wochenschr 1972;97:443-8.

23. Chapman I. Relationships of recent coronary artery occlusion and acute myocardial infarction. 7 Mt Sinai Hosp N Y 1968;35:149-54.

24. Spain D. Pathologic spectrum of myocardial infarction. In: Likoff $W$, Segal $\mathrm{B}$, Insull W, et al, editors. Atherosclerosis and coronary heart disease. New York: Grune \& Stratton; 1972. p. 133-9.

25. Davies MJ, Woolf N, Robertson WB. Pathology of acute myocardial infarction with particular reference to occulsive coronary thrombi. Br Heart $\mathcal{F}$ 1976;38:659-64.

26. Dawood MM, Gutpa DK, Southern J, Walia A, Atkinson JB, Eagle KA Pathology of fatal perioperative myocardial infarction: implications regarding pathophysiology and prevention. Int 7 Cardiol 1996;57:37-44.

27. Cohen MC, Aretz TH. Histological analysis of coronary artery lesions in fatal postoperative myocardial infarction. Cardiovasc Pathol 1999;8:133-9.

28. Landesberg G. The pathophysiology of perioperative myocardial infarction: facts and perspectives. 7 Cardiothorac Vasc Anesth 2003;17:90-100.

29. Ellis SG, Hertzer NR, Young JR, Brener S. Angiographic correlates of cardiac death and myocardial infarction complicating major nonthoracic vascular surgery. Am 7 Cardiol 1996;77:1126-8.

30. Schillinger M, Domanovits $H$, Bayegan $K$, Holzenbein T, Grabenwoger $M$ Thoenissen J, et al. C-reactive protein and mortality in patients with acute aortic disease. Intensive Care Med 2002;28:740-5.

31. Rosenfeld BA, Beattie C, Christopherson R, Norris EJ, Frank SM, Breslow $\mathrm{MJ}$, et al. The effects of different anesthetic regimens on fibrinolysis and the development of postoperative arterial thrombosis. Perioperative Ischemia Randomized Anesthesia Trial Study Group. Anesthesiology 1993;79:435-43.

32. Sametz W, Metzler H, Gries M, Porta S, Sadjak A, Supanz S, et al. Perioperative catecholamine changes in cardiac risk patients. Eur 7 Clin Invest 1999:29:582-7

33. Parker SD, Breslow MJ, Frank SM, Rosenfeld BA, Norris EJ, Christopherson $\mathrm{R}$, et al. Catecholamine and cortisol responses to lower extremity revascularization: correlation with outcome variables. Perioperative Ischemia Randomized Anesthesia Trial Study Group. Crit Care Med 1995;23:1954-61.

34. Mahla E, Tiesenhausen K, Rehak P, Fruhwald S, Purstner P, Metzler H. Perioperative myocardial cell injury: the relationship between troponin $\mathrm{T}$ and cortisol. 7 Clin Anesth 2000;12:208-12.

35. Shoemaker WC, Appel PL, Kram HB. Tissue oxygen debt as a determinant of lethal and nonlethal postoperative organ failure. Crit Care Med 1988;16: 1117-20.

36. Kluft C, Verheijen JH, Jie AF, Rijken DC, Preston FE, Sue-Ling HM, et al. The postoperative fibrinolytic shutdown: a rapidly reverting acute phase pattern for the fast-acting inhibitor of tissue-type plasminogen activator after trauma. Scand 7 Clin Lab Invest 1985;45:605-10.

37. Mahdy AM, Galley HF, Abdel-Wahed MA, el-Korny KF, Sheta SA, Webster NR. Differential modulation of interleukin- 6 and interleukin-10 by diclofenac in patients undergoing major surgery. Br F Anaesth 2002;88:797-802.

38. Cruickshank AM, Fraser WD, Burns HJ, Van Damme J, Shenkin A. Response of serum interleukin-6 in patients undergoing elective surgery of varying severity. Clin Sci (Lond) 1990;79:161-5.

39. Chambrier C, Chassard D, Bienvenu J, Saudin F, Paturel B, Garrigue C, et al. Cytokine and hormonal changes after cholecystectomy. Effect of ibuprofen pretreatment. Ann Surg 1996;224:178-82.

40. Scherer MA, Neumaier M, von Gumppenberg S. C-reactive protein in patients who had operative fracture treatment. Clin Orthop Relat Res 2001;393: 287-93.

41. Blake GJ, Ridker PM. Inflammatory bio-markers and cardiovascular risk prediction. F Intern Med 2002;252:283-94.

42. Baxevanis CN, Papilas K, Dedoussis GV, Pavlis T, Papamichail M. Abnormal cytokine serum levels correlate with impaired cellular immune responses after surgery. Clin Immunol Immunopathol 1994;71:82-8.

43. Flinn WR, McDaniel MD, Yao JS, Fahey VA, Green D. Antithrombin III deficiency as a reflection of dynamic protein metabolism in patients undergoing vascular reconstruction. 7 Vasc Surg 1984;1:888-95.

44. McDaniel MD, Pearce WH, Yao JS, Rossi EC, Fahey VA, Green D, et al. Sequential changes in coagulation and platelet function following femorotibial bypass. 7 Vasc Surg 1984;1:261-8.

45. Breslow MJ, Parker SD, Frank SM, Norris EJ, Yates H, Raff H, et al. Determinants of catecholamine and cortisol responses to lower extremity revascularization. PIRAT Study Group. Anesthesiology 1993;79:1202-9.

46. Chernow B, Alexander HR, Smallridge RC, Thompson WR, Cook D, Beardsley $\mathrm{D}$, et al. Hormonal responses to graded surgical stress. Arch Intern Med 1987; $147: 1273-8$

47. Frank SM, Higgins MS, Breslow MJ, Fleisher LA, Gorman RB, Sitzmann JV, et al. The catecholamine, cortisol, and hemodynamic responses to mild perioperative hypothermia. A randomized clinical trial. Anesthesiology 1995;82:83-93.

48. Udelsman R, Norton JA, Jelenich SE, Goldstein DS, Linehan WM, Loriaux DL, et al. Responses of the hypothalamic-pituitary-adrenal and reninangiotensin axes and the sympathetic system during controlled surgical and anesthetic stress. 7 Clin Endocrinol Metab 1987;64:986-94.

49. Moller IW, Dinesen K, Sondergard S, Knigge U, Kehlet H. Effect of patientcontrolled analgesia on plasma catecholamine, cortisol and glucose concentrations after cholecystectomy. Br 7 Anaesth 1988;61:160-4.

50. Priebe HJ. Triggers of perioperative myocardial ischaemia and infarction. $\mathrm{Br}$ 7 Anaesth 2004;93:9-20.

51. Weissman C. The metabolic response to stress: an overview and update. Anesthesiology 1990;73:308-27.

52. Fleisher LA, Nelson AH, Rosenbaum SH. Postoperative myocardial ischemia: etiology of cardiac morbidity or manifestation of underlying disease? 7 Clin Anesth 1995;7:97-102.

53. Landesberg G, Mosseri M, Zahger D, Wolf Y, Perouansky M, Anner H, et al. Myocardial infarction after vascular surgery: the role of prolonged stress-induced, ST depression-type ischemia. 7 Am Coll Cardiol 2001;37:1839-45.

54. Schug SA, Torrie JJ. Safety assessment of postoperative pain management by an acute pain service. Pain 1993;55:387-91.

55. Nelson AH, Fleisher LA, Rosenbaum SH. Relationship between postoperative anemia and cardiac morbidity in high-risk vascular patients in the intensive care unit. Crit Care Med 1993;21:860-6.

56. Frank SM, Beattie C, Christopherson R, Norris EJ, Perler BA, Williams GM, et al. Unintentional hypothermia is associated with postoperative myocardial ischemia. Perioperative Ischemia Randomized Anesthesia Trial Study Group. Anesthesiology 1993;78:468-76.

57. Goldman L, Caldera DL, Nussbaum SR, Southwick FS, Krogstad D, Murray $\mathrm{B}$, et al. Multifactorial index of cardiac risk in noncardiac surgical procedures. N Engl 7 Med 1977;297:845-50.

58. Larsen SF, Olesen KH, Jacobsen E, Nielsen H, Nielsen AL, Pietersen A, et al. Prediction of cardiac risk in non-cardiac surgery. Eur Heart 7 1987;8:179-85.

59. Gilbert K, Larocque BJ, Patrick LT. Prospective evaluation of cardiac risk in dices for patients undergoing noncardiac surgery. Ann Intern Med 2000;133: $356-9$

60. Chan A, Livingstone D, Tu J. The Goldman and Detsky cardiac-risk indices: Do they work in patients undergoing hip-fracture surgery? Ann R Coll Physicians Surg Can 1999;32:337-41.

61. McGinn T, Guyatt G, Wyer P, Naylor C, Stiell I. Clinical prediction rules. In: Guyatt $\mathrm{G}$, Rennie D, editors. Users' guides to the medical literature. Chicago (IL): AMA Press; 2002. p. 471-83.

62. Kertai MD, Boersma E, Bax JJ, Heijenbrok-Kal MH, Hunink MG, L'Talien GJ, et al. A meta-analysis comparing the prognostic accuracy of six diagnostic tests for predicting perioperative cardiac risk in patients undergoing major vascular surgery. Heart 2003;89:1327-34.

63. Etchells E, Meade M, Tomlinson G, Cook D. Semiquantitative dipyridamole myocardial stress perfusion imaging for cardiac risk assessment before noncardiac vascular surgery: a meta-analysis. 7 Vasc Surg 2002:36:534-40.

64. Halliburton B, Bell D, Preston J. AANA Journal course: Update for nurse anesthetists. Part 4: preoperative cardiac evaluation. AANA 7 2004;72:365-71.

65. Almanaseer Y, Mukherjee D, Kline-Rogers EM, Kesterson SK, Sonnad SS, Rogers B, et al. Implementation of the ACC/AHA guidelines for preoperative cardiac risk assessment in a general medicine preoperative clinic: improving efficiency and preserving outcomes. Cardiology 2005;103:24-9.

66. Eagle KA, Berger PB, Calkins H, Chaitman BR, Ewy GA, Fleischmann KE, et al. ACC/AHA guideline update for perioperative cardiovascular evaluation for noncardiac surgery - executive summary: a report of the American College of Cardiology/American Heart Association Task Force on Practice Guidelines (Committee to Update the 1996 Guidelines on Perioperative Cardiovascular Evaluation for Noncardiac Surgery). 7 Am Coll Cardiol 2002;39: 542-53.

67. Back MR, Schmacht DC, Bowser AN, Stordahl N, Cuthbertson D, Johnson $\mathrm{BL}$, et al. Critical appraisal of cardiac risk stratification before elective vascular surgery. Vasc Endovascular Surg 2003;37:387-97.

68. Samain E, Farah E, Leseche G, Marty J. Guidelines for perioperative cardiac evaluation from the American College of Cardiology/American Heart Association task force are effective for stratifying cardiac risk before aortic surgery. $\mathcal{F}$ Vasc Surg 2000;31:971-9.

69. Taher T, Khan NA, Devereaux PJ, Fisher BW, Ghali WA, McAlister FA. Assessment and reporting of perioperative cardiac risk by Canadian general in ternists: art or science? 7 Gen Intern Med 2002;17:933-6.

Correspondence to: Dr. P.J. Devereaux, Department of Clinical Epidemiology and Biostatistics, Faculty of Health Sciences, Rm. 2C8, McMaster University, 1200 Main St. W, Hamilton ON L8N 3Z5; fax 905905 526-1353; philipj@mcmaster.ca 